Document downloaded from:

http://hdl.handle.net/10251/158947

This paper must be cited as:

Añón, E.; Costero, AM.; Amorós Del Toro, P.; El Haskouri, J.; Martínez-Máñez, R.; Parra Álvarez, M.; Gil Grau, S.... (2020). Peptide-Capped Mesoporous Nanoparticles: Toward a more Efficient Internalization of Alendronate. ChemistrySelect. 5(12):3618-3625.

https://doi.org/10.1002/slct.202000417

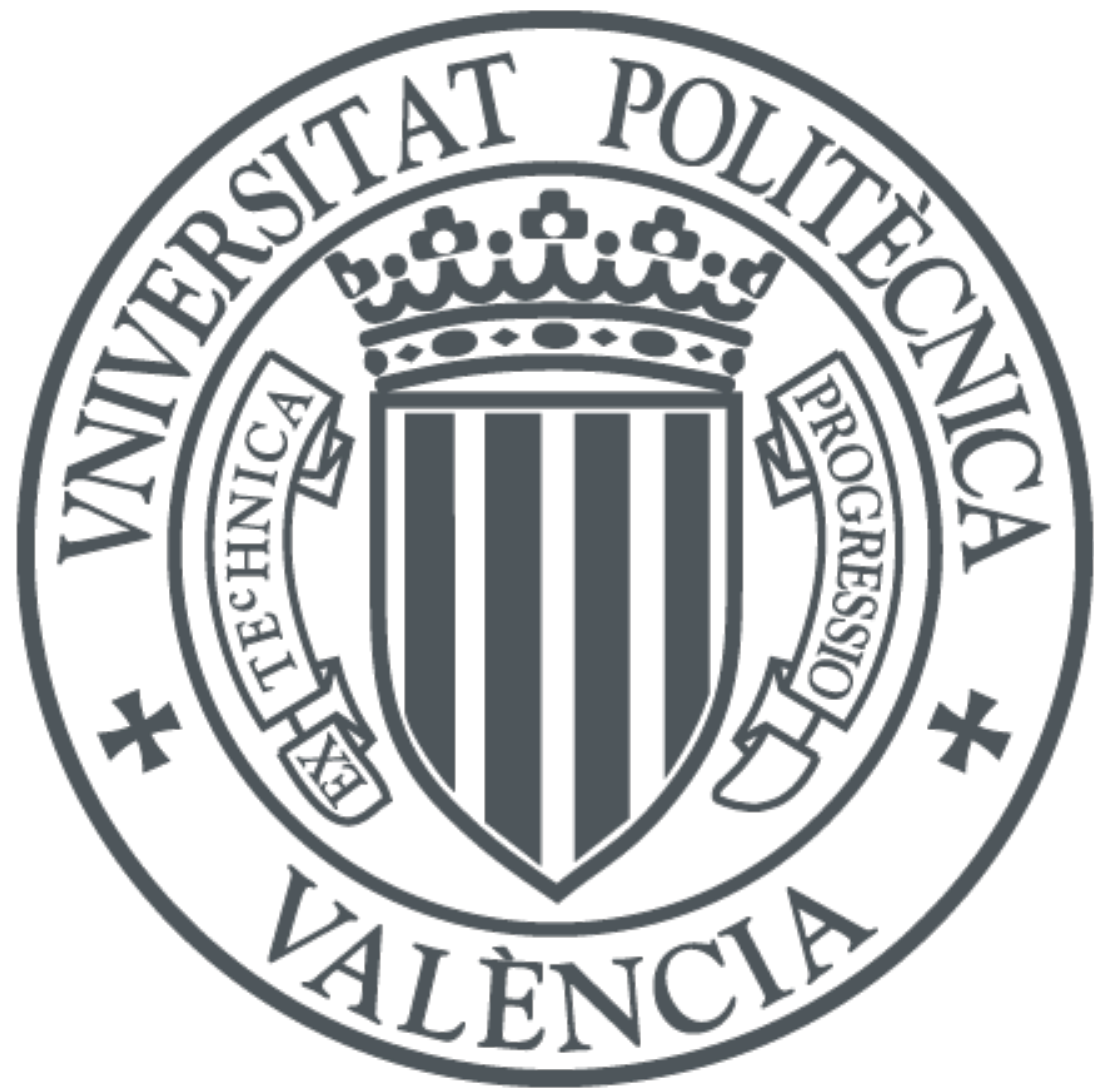

The final publication is available at

https://doi.org/10.1002/slct.202000417

Copyright John Wiley \& Sons

Additional Information

This is the peer reviewed version of the following article: E. Añón, A. M. Costero, P. Amorós, J. El Haskouri, R. Martínez-Mánez, M. Parra, S. Gil, P. Gaviña, M. C. Terencio, M. Alfonso, ChemistrySelect 2020, 5, 3618., which has been published in final form at https://doi.org/10.1002/slct.202000417. This article may be used for non-commercial purposes in accordance with Wiley Terms and Conditions for Self-Archiving. 


\title{
Peptide-Capped Mesoporous Nanoparticles: Toward a more Efficient Internalization of Alendronate
}

\author{
Elena Añón, ${ }^{[a]}$ Ana M. Costero, ${ }^{\left[{ }^{[b]}\right]}$ Pedro Amorós, ${ }^{[c]}$ Jamal El Haskouri, ${ }^{[c]}$ Ramón Martínez-Mánez, ${ }^{[d]}$ \\ Margarita Parra, ${ }^{[b]}$ Salvador Gil, ${ }^{[b]}$ Pablo Gaviña, ${ }^{[b]}$ M. Carmen Terencio, ${ }^{*[e]}$ and María Alfonso ${ }^{[f]}$
}

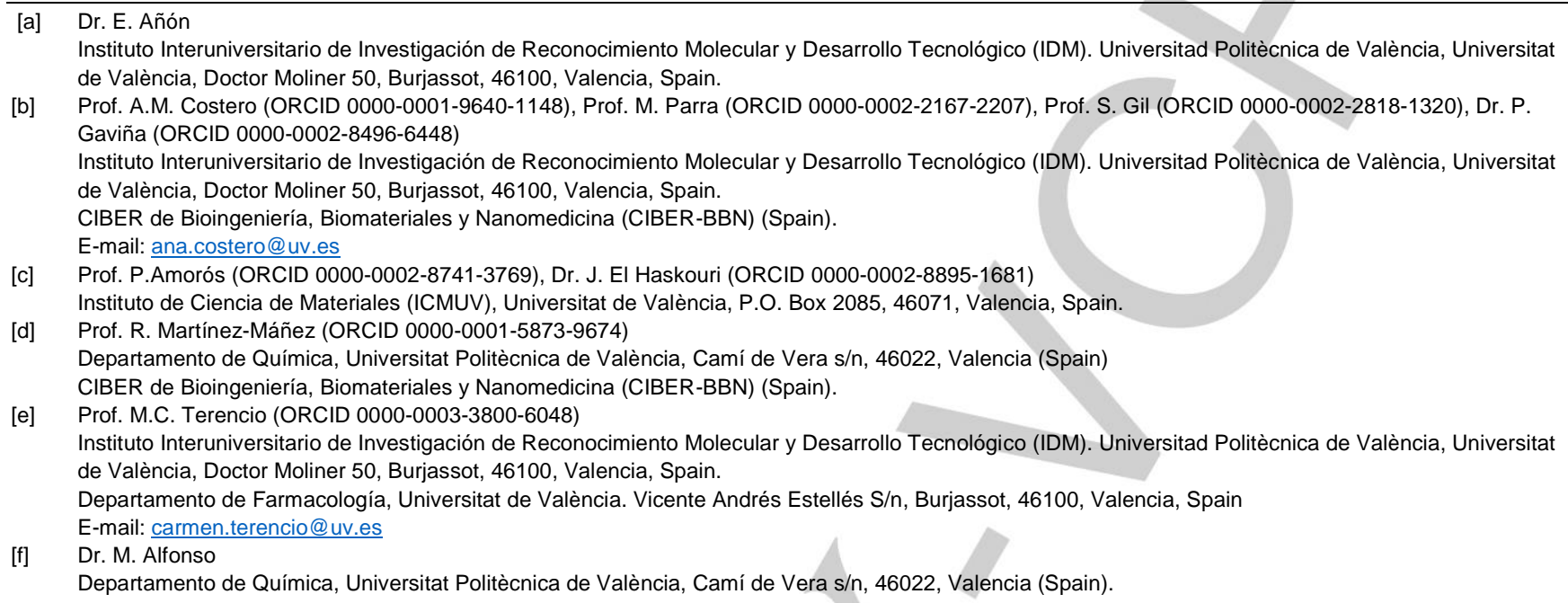

Supporting information for this article is given via a link at the end of the document

\begin{abstract}
Osteoporosis is an illness which appears when the osteoblast/osteoclast activities are unbalanced taking place bone resorption (caused by osteoclasts) in higher extension than bone formation (induced by osteoblasts). Alendronate is one of the most used drugs for osteoporosis treatment despite its scarce bioavailability. Here we present the synthesis and characterization of mesoporous gated nanoparticles (two sets) for the controlled release of alendronate. The first set of nanoparticles (S1) were loaded with sulforhodamine $\mathrm{B}$ and capped with a peptide that could be selectively hydrolyzed by cathepsin K enzyme (overexpressed in osteoclasts). The second set (S2) was functionalized with aminopropyl moieties, loaded with nitrobenzofurazan labelled alendronate and capped with the same peptide. Both nanoparticles were internalized by RAW 264.7 macrophages (which could differentiate in osteoclasts) and were able to release its entrapped cargo in the presence of cathepsin $\mathrm{K}$ added in the macrophage lysates. Using S2 nanoparticles $4.2 \%$ of the total alendronate amount in contact with the cells is liberated inside them and could produce its therapeutic effect.
\end{abstract}

\section{Introduction}

Osteoporosis is an illness characterized by producing a systemic skeletal disorder, which results in a reduction of bone strength, an increase in susceptibility to fractures and skeletal fragility and an interruption of the bone micro architecture. Osteoporosis appears when the osteoblast/osteoclast activities are unbalanced taking place bone resorption (caused by osteoclasts) in higher extension than bone formation (induced by osteoblasts). Osteroporosis is widespread and it is a major problem, either from the economic and healthcare point of view, as it affects 1 in 2 women and 1 in 5 men. At present there are multiple therapeutic options available for osteoporosis treatment ${ }^{[1]}$ but the use of oral bisphosphonates is the first choice because of the accumulated experience in their use and their price. Among bisphosphonates, alendronate is the most used drug. ${ }^{[2]}$ Its mechanism of action has been linked to the induction of apoptosis in osteoclasts and thus the reduction of osteoclastmediated bone resorption. ${ }^{[3]}$ Despite its widespread use, alendronate has one major drawback: a scarce $0.67 \%$ bioavailability. ${ }^{[4]}$

On the other hand, the use of nanomaterials for drug delivery has demonstrated to be an appropriate alternative for improving drug bioavailability. ${ }^{[5]}$ Combination of nanomaterials with drugs can lead to nanoformulations which improved active compound bioavailability and also allowed, in certain cases, controlled release of the cargo. Micelles, liposomes, organic polymers, dendrimers and inorganic nanoparticles are the most common used supports to prepare active nanoformulations. ${ }^{[6]}$ Among them, mesoporous silica nanoparticles have attracted great attention due to their remarkable features such as inertness, biocompatibility, pores in the $2-3 \mathrm{~nm}$ range (which allowed the loading of high amounts of cargo), high specific volume and easy functionalization using the well-known alkoxysilane chemistry (which allowed the grafting of selected molecules acting as targeting ligands or as capping ensembles). ${ }^{[7]}$ Taking into account the above cited properties, mesoporous silica nanoparticles have been extensively used for the storage and release of highly hydrophobic drugs in several pharmaceutical applications. ${ }^{[8]}$ In fact, mesoporous silica scaffolds have already been used for the controlled release of alendronate in order to overcome its poor water solubility. ${ }^{[9]}$ 


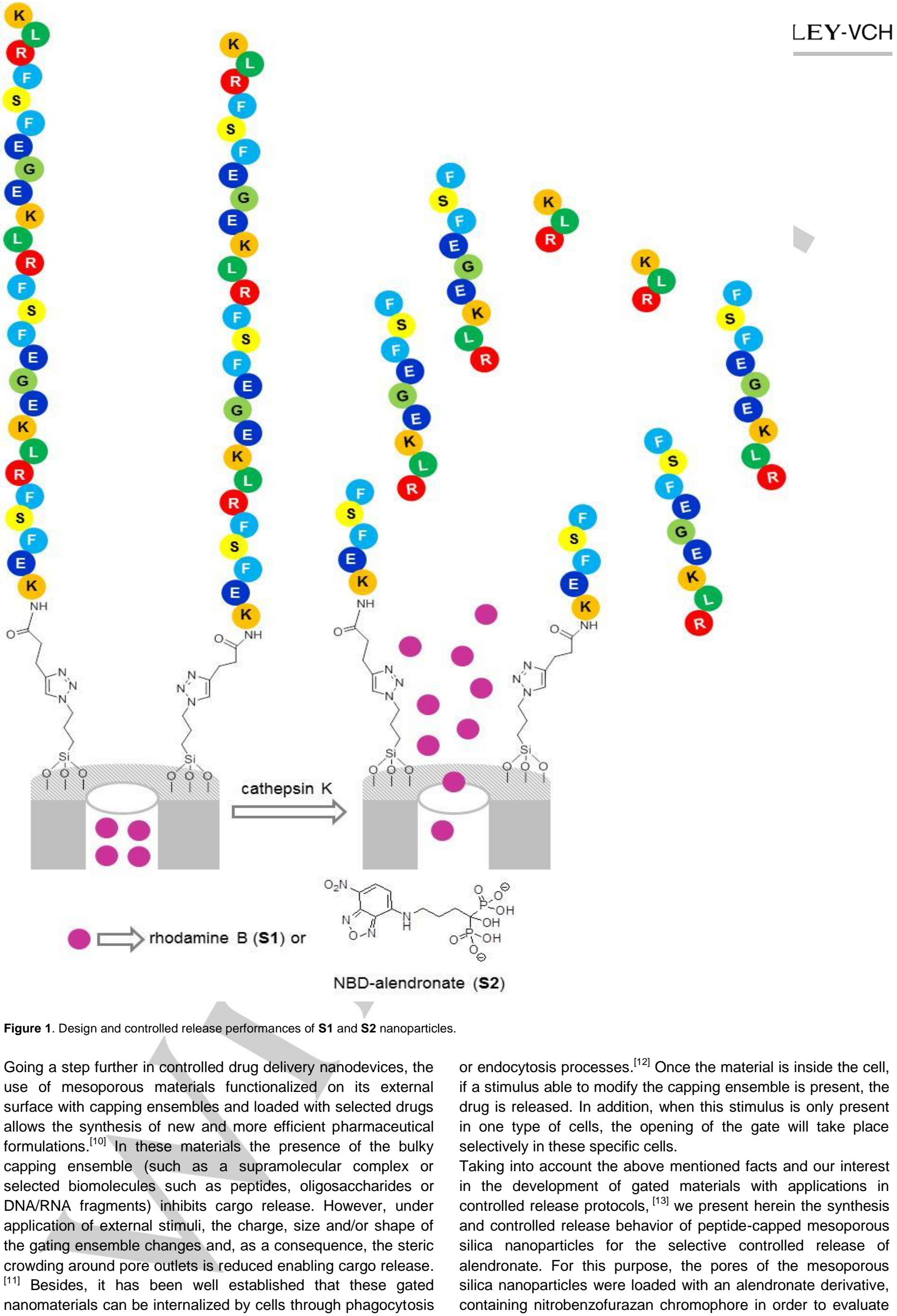


its release using UV-visible measurements, and the external surface was functionalized, using an alkyne-azide "click" coupling reaction, with a peptide able to be hydrolyzed by cathepsin $\mathrm{K}$ enzyme. Cathepsin $\mathrm{K}$ is a proteolytic enzyme that is expressed in osteoclasts and multinucleated giant cells ${ }^{[14]}$ and is also able to preferentially hydrolyze specific amide bonds in some peptides. ${ }^{[15]}$ The prepared materials are depicted in Figure
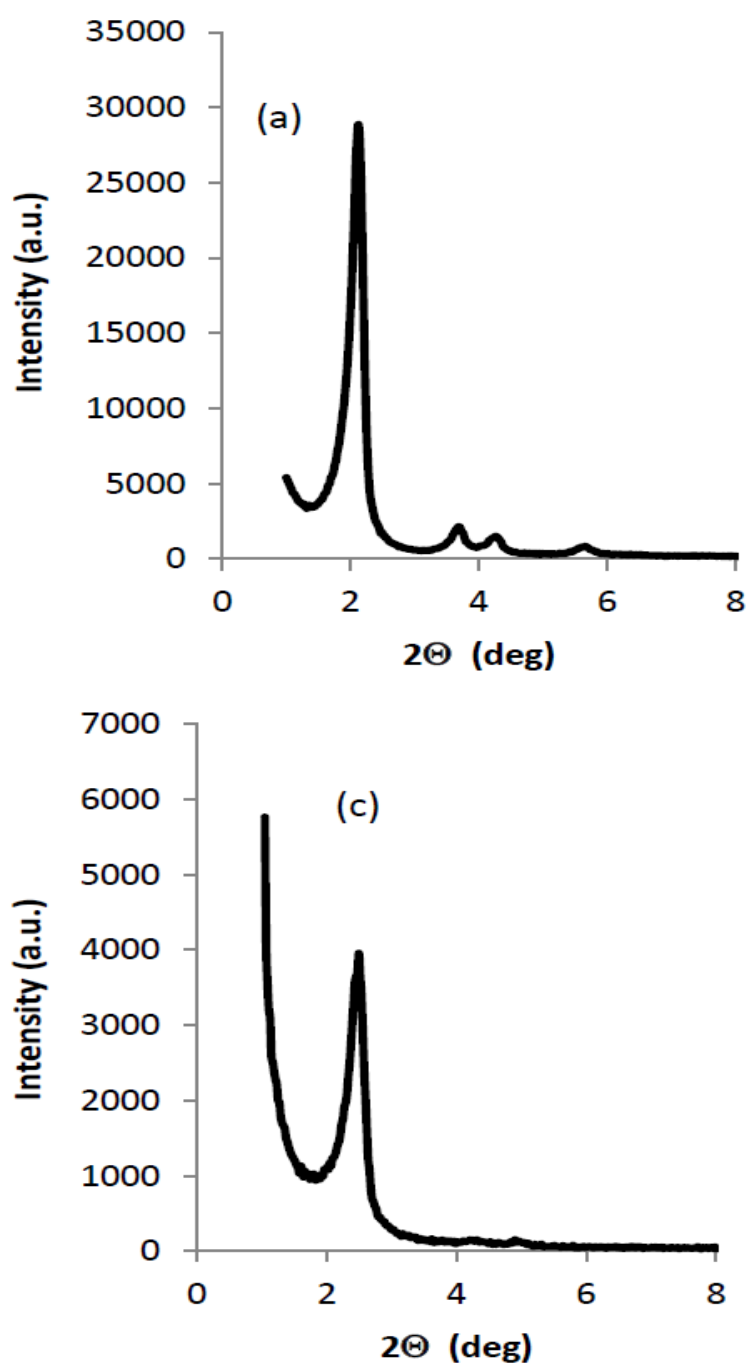

1 (S1 and S2 loaded with sulforhodamine B and with the derivatized alendronate respectively). It was expected that the presence of a bulky peptide grafted onto the external surface of the nanoparticles inhibited cargo release whereas in the presence of cathepsin $\mathrm{K}$ a marked payload delivery should be observed (due to enzymatic hydrolysis of the peptide capping ensemble).
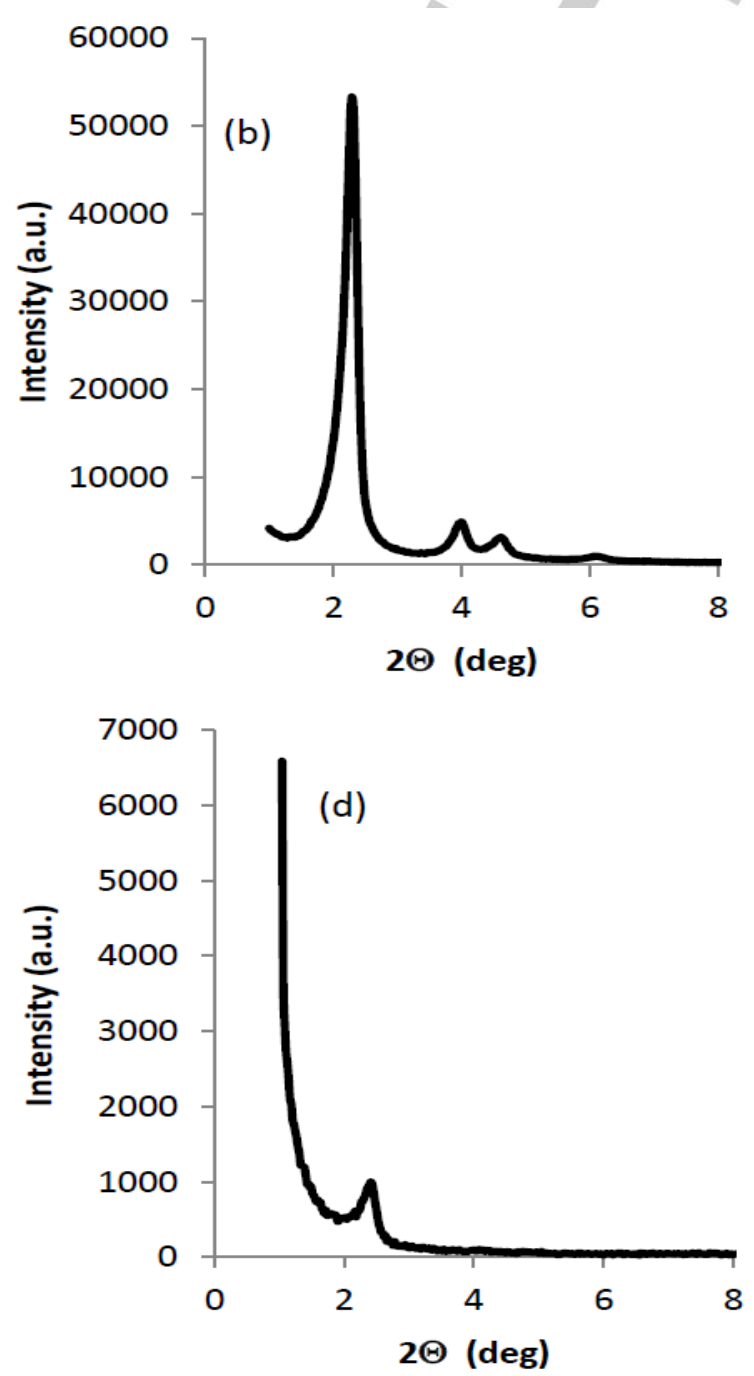

Figure 2. PXRD patterns of (a) as-synthesized MCM-41 nanoparticles; (b) calcined MCM-41 nanoparticles; (c) S1; (d) S2

\section{Results and Discussion}

Design and synthesis of gated materials

Two gated nanoparticles were prepared, S1 loaded with sulforhodamine B and $\mathbf{S} 2$ loaded with an alendronate derivative. For the synthesis of both materials, mesoporous silica nanoparticles (prepared using cetyltrimethylammonium bromide as structure directing agent and tetraethylorthosilicate as silica source ${ }^{[16]}$ were used. Then, for $\mathbf{S 1}$, the pores of the inorganic scaffold were loaded with sulforhodamine B and then the external surface functionalized with azidopropyl)triethoxysilane. Finally, the external surface was decorated with a selected peptide (ác. Pentinoico)-NH-
KEFSFRLKEGEFSFRLKEGEFSFRLK-Ac using an alkyne-azide "click" coupling reaction. The selection of the peptide was based on data in the literature that indicated that this sequence could be selectively (or in a major extension) hydrolyzed in presence of cathepsin $\mathrm{K}$ when compared with other enzymes of the cathepsin series [27]. On the other hand, S2 material was prepared using a slightly modified procedure. In a first step alendronate was labelled with 4-chloro-7-nitrobenzofurazan yielding a derivative containing NBD chromophore (NBDalendronate) with absorption bands at $475\left(\varepsilon=19500 \mathrm{M}^{-1} \mathrm{~cm}^{-1}\right)$ and $350\left(\varepsilon=8160 \mathrm{M}^{-1} \mathrm{~cm}^{-1}\right) \mathrm{nm}^{[17]}$ (see figure $\mathrm{S} 1$ in the supporting information). In a second step, the mesoporous silica nanoparticles were decorated with aminopropyl moieties (mainly onto the inner of the pores but certain external surface 
functionalization could not be discarded) in order to impart the inner surface with positive charge which facilitates NBDalendronate loading. ${ }^{[9]}$ Then, the pores were loaded with NBDalendronate and the external surface was decorated with azidopropyl moieties. Finally, solid S2 was prepared after the grafting of selected peptide using an alkyne-azide "click" coupling reaction.

\section{Characterization of the prepared materials}

The as-made MCM-41 nanoparticles, calcined solid, S1 and S2 were characterized using powder X-ray diffraction (PXRD), transmission electron microscopy (TEM), $\mathrm{N}_{2}$ adsorptiondesorption isotherms, elemental analysis, DLS and zeta potential measurements. PXRD patters of as made and calcined MCM-41 nanoparticles showed the four mesoporous characteristic low-angle peaks (100), (110), (200), (210) corresponding to a hexagonal-ordered array (see Figure 2). Besides, as expected, the MCM-41 calcined nanoparticles present a significant shift of (100) reflection due to the cell contraction induced by the condensation of silanol groups during the calcination process. On the other hand, S1 and S2 show lower PXRD signal intensities when compared to the parent silica (see also Figure 2). The intensity decrease is clearly appreciated in the most intense (100) reflection, being especially important in S2. However, PXRD pattern of $\mathbf{S 1}$ still preserve two additional (110) and (200) reflections of lower intensity, while in the case of $\mathbf{S 2}$ all signals disappear (in the background of the spectra) with the exception of the (100) peak. This behavior, is most likely due to the contrast lowering between the pore walls and the pore voids that must occurs after the loading/functionalization process. The fact that it is more pronounced for $\mathbf{S} 2$ than for $\mathbf{S 1}$ and can be associated with two factors, the functionalization of $\mathbf{S 2}$ with aminopropyl moieties (with a high proportion located in the inner of the pores) and probably with a higher charge of alendronate than of sulforhodamine B in S1. Nevertheless, the preservation in both materials (S1 and $\mathbf{S 2}$ ) of the (100) reflection in the PXRD patterns strongly evidences that the mesoporous scaffold is maintained in the final gated nanoparticles.

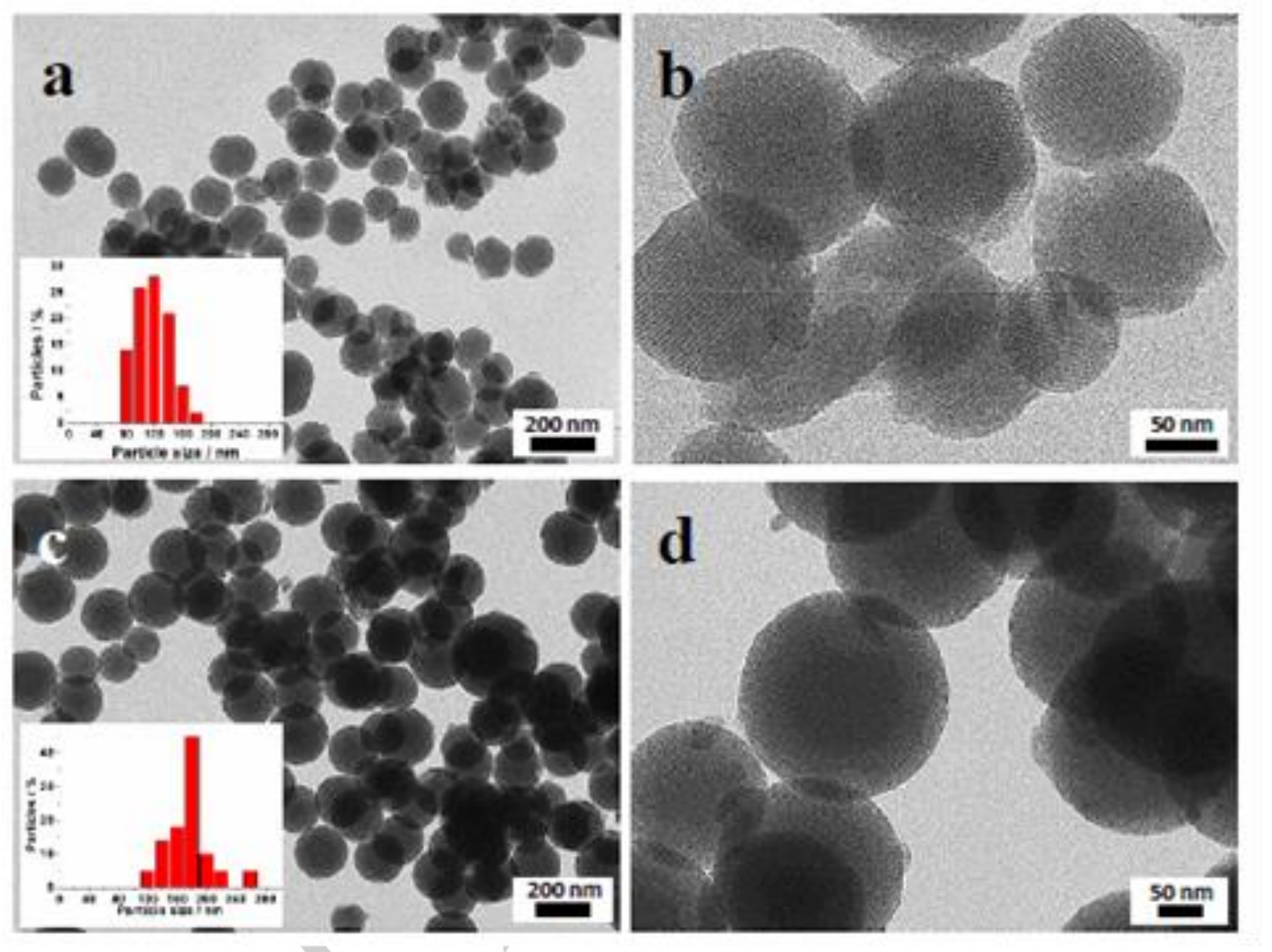

Figure 3. Representative TEM images of $(a, b) \mathbf{S 1}$ and (c,d) S2 nanoparticles. Inset in a) and c) particles size distribution.

On the other hand, TEM images in Figure 3 show that the morphology of both samples, $\mathbf{S 1}$ and $\mathbf{S 2}$, can be described as relatively dispersed spherical particles. We achieve, in both cases, a high homogeneity in particle sizes (see insets in Figure 3), with averaged diameters of 117 and $172 \mathrm{~nm}$ for S1 and S2, respectively. Furthermore, TEM images confirm, as expected according to PXRD data, the presence of mesopores (as white spots, appreciated in the high magnification images in Figures
$3 b$ and $3 d)$. These white spots are more visible in the case of $\mathbf{S 1}$ than in S2. This fact probably is due to a combination of two factors: the relatively higher values of particle size and loading (see below) in the case of $\mathbf{S 2}$.

The amount of loaded sulforhodamine B in $\mathbf{S 1}(0.98 \mathrm{mg} / 100 \mathrm{mg}$ solid) was measured by fluorescence after nanoparticles disaggregation in concentrated $\mathrm{NaOH}$ (see figure $\mathrm{S} 2$ in the supporting information). Besides, the amount of phosphorus in 
S2 nanoparticles was measured by ICP coupled with mass spectrometry. The phosphorus determined accounted for the amount of NBD-alendronate loaded into the pores of $\mathbf{S 2}$ nanoparticles $(8.23 \mathrm{mg} / 100 \mathrm{mg}$ solid). On the other hand, the organic matter grafted onto the external surface of S1 and S2 was evaluated by elemental analysis and the obtained values are included in Table 1. From these data, it can be deduced that the lower size of the labeled alendronate compared to the sulforhodamine $\mathrm{B}$, along with the electrostatic interaction between alendronate anions and the protonated propilamine groups, are factors that work in a cooperative way to significantly increase the drug loading when compared to sulforhodamine B incorporation. These data correlate with the previous characterization through PXRD and TEM. Finally, a similar functionalization degree (preferently on the external surface of the particles) has been achieved for $\mathbf{S 1}$ and $\mathbf{S 2}$. This could be related with the similar size of the $\mathbf{S 1}$ and $\mathbf{S} 2$ particles. The slightly higher value of organic material bounded to the silica surface in the case of $\mathbf{S 2}$ (despite its larger size) must be associated with the functionalization with propylamine groups, that also can be incorporated in a certain proportion inside the mesopores.

Table 1. Data of cargo inside the nanoparticles and organic material outside the pores

\begin{tabular}{|c|c|c|c|c|c|c|c|}
\hline Solid & $\begin{array}{l}\text { Mg cargo/100 } \\
\text { mg material }\end{array}$ & $\begin{array}{l}\text { mg organic } \\
\text { material } \\
\text { bonded/100 mg } \\
\text { material }\end{array}$ & $\begin{array}{l}S_{\text {BET }} \\
\left(m^{2} g^{-1}\right)\end{array}$ & $\begin{array}{l}\text { Mesopore } \\
\text { volume } \\
\left(\mathrm{cm}^{3} \mathrm{~g}^{-1}\right)^{[\mathrm{b}]}\end{array}$ & $\begin{array}{l}\text { Mesopore size } \\
(\mathrm{nm})^{[\mathrm{b}]}\end{array}$ & $\begin{array}{l}\text { Textural pore } \\
\text { volume } \\
\left(\mathrm{cm}^{3} \mathrm{~g}^{-1}\right)^{[b]}\end{array}$ & $\begin{array}{l}\text { Textural pore } \\
\text { size }(n m)^{[b]}\end{array}$ \\
\hline S1 & 0.98 & 39 & 375 & 0.13 & 2.00 & 0.32 & $>100$ \\
\hline S2 & 8.23 & $42^{[a]}$ & 113 & 0.02 & - & 0.37 & $>100$ \\
\hline
\end{tabular}

[a] Include both the peptide that acts as molecular gate and the amine used in the amination reaction. [b] Values determined by application of the BJH model on the adsorption branch of the isotherms.

The shape of the $\mathrm{N}_{2}$ adsorption-desorption isotherms shown in Figure 4 is typical of mesoporous silica materials with restricted access to the mesopores. The typical adsorption step at intermediate relative partial pressure values (associated to the filling of the surfactant generated mesopores) which is still visible for the $\mathbf{S} 1$ solid, practically disappears in the case of the S2 material. This difference can be quantified from the data gathered in Table 1. The low BET surface area and the absence of mesopore volume in the case of $\mathbf{S 2}$ indicates that the only accessible surface for the $\mathrm{N}_{2}$ must be the external shell of the particles. This fact is consistent with the presence of a double organic functionalization and the high alendronate loading. In the case of $\mathbf{S 1}$, the lower dye charge and the simple functionalization still leave some accessibility to the interior of the mesopores. This results in higher BET area and BJH mesopore volume. On the other hand, a similar textural (interparticle) porosity is observed in both cases as consequence of the packing of silica spheres with similar size. The slightly higher textural pore volume measured for $\mathbf{S} 2$ when compared to $\mathbf{S 1}$, could be due to two factors: the larger size of the $\mathbf{S 2}$ particles (leading to a larger size of the inter-particle macropores) and to the existence of a more pronounced trend towards aggregation (see below).

Figure 4. $\mathrm{N}_{2}$ adsorption desorption isotherms of samples (a) $\mathbf{S} 1$ and (b) $\mathbf{S 2}$. In order to evaluate the dispersibility of $\mathbf{S} \mathbf{1}$ and $\mathbf{S} \mathbf{2}$ nanoparticles, a protocol including ultrasound irradiation and posterior filtration was optimized. Without this treatment in both cases we observe, through DLS, the presence of a certain amount of large aggregates of ca. $2 \mu \mathrm{m}$. However, after our optimized procedure the size of the grains decreases in a marked way up to ca. 122 and $\mathbf{3 5 0} \mathrm{nm}$ for samples $\mathbf{S 1}$ and $\mathbf{S 2}$, respectively. In the case of S1, this value fits very well with the average diameter determined through TEM. Hence, we can assume that the dispersion of the $\mathbf{S 1}$ sample is complete in the form of isolated particles. On the contrary, some aggregation occurs for S2. The size of the grains measured by DLS is ca. 2-fold of the particle diameter estimated by TEM. This fact is indicative of a relatively low aggregation degree of the individual nanoparticles compatible with a mixture of isolated particles and small clusters formed from two or three particles. This different tendency towards aggregation must be associated with the organic groups

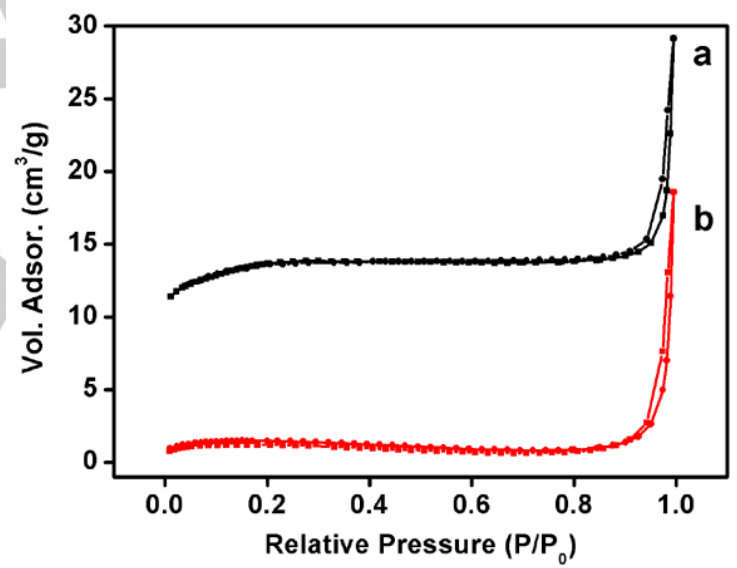

located at the external surface of the particles. We have measured the values of the $\zeta$-potential for $\mathbf{S 1}(-15.7 \mathrm{mV})$ and $\mathbf{S 2}$ $(-6.4 \mathrm{mV})$ samples in water. The decrease in the $\zeta$-potential value in $\mathbf{S 2}$ could be due to the functionalization with aminopropyl groups which, being partially protonated at neutral $\mathrm{pH}$, diminish the negative surface charge of the silica, leading to a more favorable aggregation.

\section{Controlled release studies}

In a first step the ability of the peptide-based molecular gates to keep the cargo inside the pores was evaluated by comparing dye liberation in both $\mathbf{S 1}$ and the corresponding uncapped nanoparticles loaded with sulforhodamine B under the same conditions with. Dye liberation in the latter material was practically instantaneous whereas in $\mathbf{S 1}$ a constant concentration of the dye in solution was achieved after around 3.5 hours (see figure S3 in the supporting information).

On the other hand, taking into account the fact that the gating peptide is composed by amino acids containing different $\mathrm{pH}$ - 
sensitive functional groups, the controlled release performances of $\mathbf{S} 1$ was tested at different $\mathrm{pH}$ values $(5.5,7.0,7.4,7.8$ and 8.0) in DMEM. For this purpose, DMEM suspensions of $\mathbf{S} 1$ at selected $\mathrm{pH}$ values were kept at room temperature for $24 \mathrm{~h}$, time enough for the total dye liberation. Then, solid was centrifuged and the sulforhodamine B emission at $590 \mathrm{~nm}$ (excitation at 565 $\mathrm{nm}$ ) in the solution measured. The obtained results showed moderate sulforhodamine B release from $\mathbf{S 1}$ nanoparticles at slightly acidic $(\mathrm{pH} 5.5)$ and basic $(\mathrm{pH} 7.8$ and 8.0) environments (see figure $\mathrm{S} 5$ in the supporting information). The smaller sulforhodamine B release was observed when $\mathbf{S 1}$ nanoparticles were suspended in DMEM at pH 7.4 in which a concentration of fluorophore of $1.9 \times 10^{-6} \mathrm{M}$ (54\% of the entrapped cargo was released) was reached (calculated using a calibration curve, see Supporting Information). Then, the release of sulforhodamine B from $\mathrm{S} 1$ nanoparticles at $\mathrm{pH} 7.4$ in the presence of cathepsin $\mathrm{K}$ $(2 \mu \mathrm{L}$ enzyme solution prepared from $25 \mu \mathrm{g}$ of cathepsin $\mathrm{K}$ in 100 $\mu \mathrm{l}$ sodium acetate/acetic acid buffer $50 \mathrm{mM}$ ) was also evaluated. The obtained results (Figure 5 ) show the emission intensity of the released sulforhodamine B from $\mathbf{S 1}$ in the absence and in the presence of cathepsin $\mathrm{K}$ after $24 \mathrm{~h}$ (see figures S3 and S4 in the supporting information for time dependent liberation and 24 $\mathrm{h}$ fluorescence spectra). As could be seen, an increase in sulforhodamine $B$ release in the presence of enzyme was observed. Using a calibration curve the amount of sulforhodamine B released was $2.8 \times 10-6 \mathrm{M}(79.5 \%$ of the entrapped fluorophore which was ca. 1.5-fold higher than the release observed in the absence of stimuli). The observed increase in sulforhodamine $B$ release could be ascribed to cathepsin K-induced hydrolysis of the grafted peptide. To establish the specificity of cathepsin $K$ in the opening mechanism control release studies with $\mathbf{S} 1$ and pronase enzyme were carried out. In these studies, pronase was unable to induce the hydrolysis of the capping peptide and the same sulforhodamine B release was observed for $\mathbf{S 1}$ in the absence and in the presence of enzyme (data not shown).

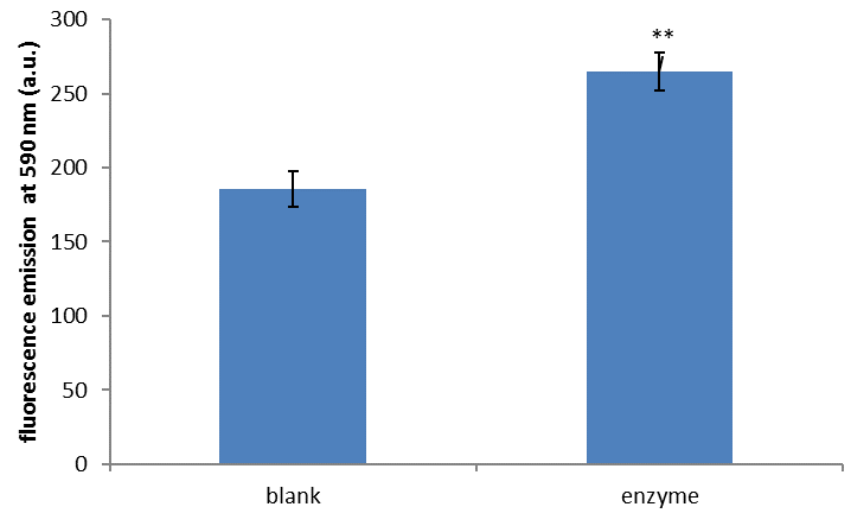

Figure 5. Sulforhodamine B released (emission at $590 \mathrm{~nm}$, excitation at 565 $\mathrm{nm}$ ) from $\mathbf{S} 1$ suspensions in DMEM at $\mathrm{pH} 7.4$ in the absence and in the presence of cathepsin $K$ after $24 \mathrm{~h}$. Data presented as mean $\pm S D(n=3)$. ${ }^{* *} p<0.01$ vs. blank (Student's test).

\section{Controlled release studies in cells}

In a first step, the viability of the peptide capped nanoparticles without loadings in RAW 264.7 macrophages was tested. RAW
264.7 macrophages were tested because there are several experimental protocols to differentiate in osteoclasts. ${ }^{[18]}$ MTT assays showed the non-toxicity of nanoparticles at different concentrations (50, 100 and $200 \mu \mathrm{g} / \mathrm{ml})$ and after 24 and $48 \mathrm{~h}$ (data not shown).

Then, in a second step, the internalization and controlled release performance of S1 in RAW 264.7 macrophages was tested. For this purpose, RAW 264.7 macrophages were seeded in 6 well plates $(2.0 \times 106$ cell/well $)$ and maintained overnight in DMEM/F12 medium containing $10 \%$ foetal calf serum and $1 \%$ penicillin/streptomycin. Then, cells were washed with fresh medium and treated with $\mathbf{S} 1(30 \mu \mathrm{g} / \mathrm{ml})$ for $24 \mathrm{~h}$. After further washing with $\mathrm{PBS}$, to eliminate not internalized particles, cells were lysed with $300 \mu$ of buffer A (10 mM HEPES, $1 \mathrm{mM}$ EDTA, $1 \mathrm{mM}$ EGTA, $10 \mathrm{mM} \mathrm{KCl}, 1 \mathrm{mM}$ DTT, $5 \mathrm{mM} \mathrm{NaF}, 1 \mathrm{mM} \mathrm{Na}_{3} \mathrm{VO}_{4}$, $10 \mathrm{mM} \mathrm{Na} \mathrm{MoO}_{4}, 1 \mu \mathrm{g} / \mathrm{ml}$ leupeptin, $0,1 \mu \mathrm{g} / \mathrm{ml}$ aprotinin, and 0,5 $\mathrm{mM}$ PMSF) during $10 \mathrm{~min}$. The cellular lysate from each well was centrifuged $(3000 \mathrm{xg}, 10 \mathrm{~min})$ and the supernatant was transferred and DMEM was added until a total volume of $6 \mathrm{~mL}$ was reached. This solution was then divided in two $3 \mathrm{~mL}$ portions. One of them was treated with cathepsin $\mathrm{K}$ whereas the other remained untreated. Finally, sulforhodamine $B$ emission in the lysates was evaluated by measuring ints emission at $590 \mathrm{~nm}$ (excitation at $565 \mathrm{~nm}$ ). All the experiments were carried out three times and the average emission value was obtained. Results are shown in Fiaure 6.

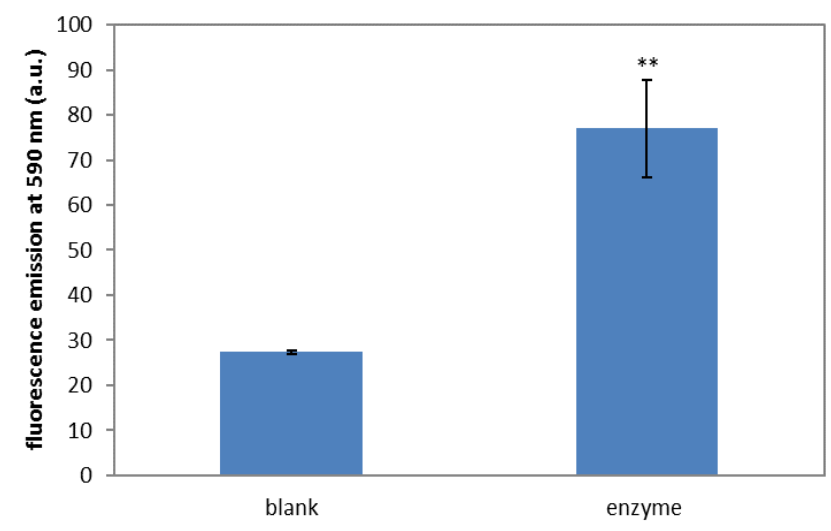

Figure 6. Sulforhodamine B (emission at $590 \mathrm{~nm}$, excitation at $565 \mathrm{~nm}$ ) presented in the lysates of RAW 264.7 macrophages treated with $\mathbf{S 1}$ in the absence (blank) and in the presence of cathepsin K (enzyme). Data presented as mean $\pm S D(n=3)$. ** $p<0.01$ vs. blank (Student's test).

As could be seen in Figure 6, in the lysates without cathepsin $\mathrm{K}$ a moderate sulforhodamine $B$ release was observed $\left(0.21 \times 10^{-6}\right.$ $M$ calculated using a calibration curve). Assuming that sulforhodamine B released from $\mathbf{S 1}$ in the lysates is the same than in the experiments carried out in DMEM (54\%) an intake of nanoparticles by RAW 264.7 macrophages of $5.4 \%$ was calculated. However, a marked sulforhodamine $B$ release in the lysate treated with cathepsin $\mathrm{K}$ was observed. The concentration of sulforhodamine $B$ in the lysate fraction treated with the enzyme was $0.7610^{-6} \mathrm{M}$ (ca. 3.6-fold enhancement). Taking into account the same nanoparticle intake $(5.4 \%)$ it could be estimated that more than $95 \%$ of the entrapped sulforhodamine $\mathrm{B}$ was released. These indirect experiments showed that $\mathrm{S} 1$ nanoparticle were properly endocytosed by RAW 264.7 macrophages and subsequent addition of cathepsin $\mathrm{K}$ to cell 
lysates induced the hydrolysis of the capping peptide with subsequent pore opening and sulforhodamine $B$ release.

Going a step further we decided to study the controlled release features of S2 nanoparticles (loaded with NBD-alendronate) under similar conditions. Again, RAW 264.7 macrophages were seeded in 6 well plates $(2.0 \times 106$ cell/well $)$ and maintained overnight in DMEM/F12 medium containing $10 \%$ foetal calf serum and $1 \%$ penicillin/streptomycin. Then, cells were washed with fresh medium and treated with $\mathbf{S 2}(30 \mu \mathrm{g} / \mathrm{ml})$ during $24 \mathrm{~h}$. After further washing with PBS, to eliminate not internalized particles, cells were lysed with $300 \mu \mathrm{l}$ of buffer A during $10 \mathrm{~min}$. The cellular lysate from each well was centrifuged, the supernatant was transferred and DMEM was added until a total volume of $6 \mathrm{~mL}$ was reached. This solution was then divided in two $3 \mathrm{~mL}$ portions. One of them was used as blank and the other was treated with cathepsin K. Then, the NBD-alendronate released was monitored by measuring the absorption band of the chromophore at $350 \mathrm{~nm}$ (see Figure 7). As could be seen in Figure 7 , the lysate fraction without enzyme showed a very small absorption indicative of nearly a negligible NBD-alendronate release. However, a marked NBD-alendronate was observed when lysate was treated with cathepsin $\mathrm{K}$ (2.68 10-6 M using an UV-visible calibration curve). Taking into account that both nanoparticles were functionalized with the same peptide and its size and external covering are quite similar, a comparable uptake by RAW 264.7 macrophages could be expected. Then, assuming an intake of $5.4 \%$ it can be determined that the release of NBD-alendronate from $\mathbf{S 2}$ nanoparticles was ca. $79.5 \%$.

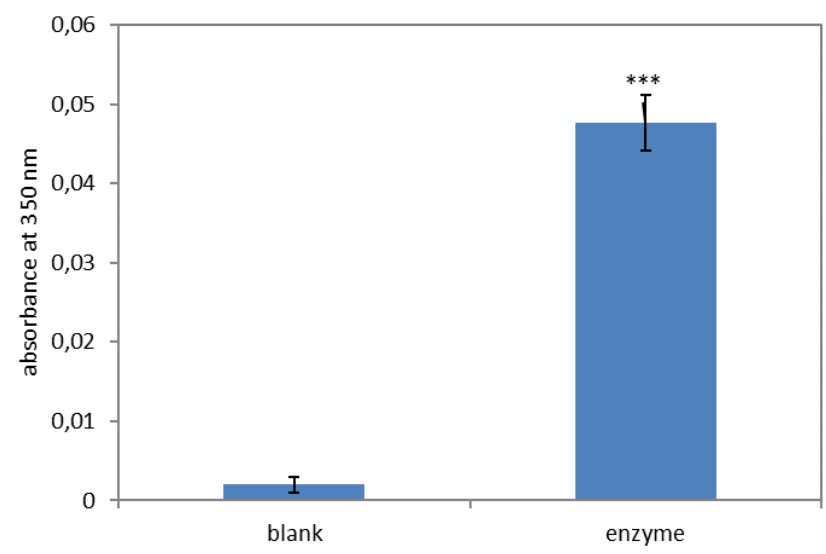

Figure 7. NBD absorption at $350 \mathrm{~nm}$ (from the NBD-alendronate released) presented in the lysates of RAW 264.7 macrophages treated with $\mathbf{S 2}$ in the absence (blank) and in the presence of cathepsin K (enzyme). Data presented as mean $\pm \operatorname{SD}(n=3) .{ }^{* * *} p<0.01$ vs. blank (Student's test).

Finally, taking into account the fact that we could calculate the total amount of NBD-alendronate in $\mathbf{S 2}$ nanoparticles administered to RAW 264.7 macrophages and the concentration of the labelled drug in the lysates (from the corresponding calibration curve), we estimated that $4.2 \%$ of the total alendronate amount in contact with the cells has been liberated inside them and could produce its therapeutic effect. Taking into account that it has been reported that bioavailability of different drugs increases when they are encapsulated in mesoporous silica nanoparticles and that $\mathbf{S} 2$ is able to go inside the cells and liberate there the labeled alendronate, we think that $\mathbf{S} 2$ presents promising properties for increasing the efficiency of osteroporosis treatment with alendronate.

\section{Conclusions}

Two new nanodevices, based MCM-41 mesoporous silica nanoparticles, loaded with sulforhodamine B (S1) and with a NBD-labelled alendronate (S2) and capped with the peptide (ác. Pentinoico)-NH-KEFSFRLKEGEFSFRLKEGEFSFRLK-Ac

(which is selectively hydrolyzed by cathepsin $K$ enzyme presented in osteoclasts) have been prepared and fully characterized. Controlled release studies, carried out with $\mathbf{S 1}$ in DMEM at $\mathrm{pH} 7.4$, showed that cathepsin $\mathrm{K}$ was able to hydrolyze the peptide allowing sulforhodamine $\mathrm{B}$ release. Besides, both solids were properly internalized by RAW 264.7 macrophages and were able to release its entrapped cargo after adding cathepsin $\mathrm{K}$ to the lysates obtained after treatment with nanoparticles. $4.2 \%$ labelled alendronate was present in the cathepsin $\mathrm{K}$ treated cells. We believe that these nanodevices could be the basis for the development of novel nanoformulations for an effective alendronate release in osteoporosis treatments.

\section{Supporting Information Summary}

Experimental section, synthesis of materials, characterization and liberation studies.

\section{Acknowledgements}

We thank the Spanish Government (RTI2018-100910-B-C41, RTI2018-100910-B-C42 (MCUI/AEI/FEDER, UE)) and the Generalitat Valenciana (PROMETEU/2018/024) for support. SCSIE (Universitat de València) is gratefully acknowledged for all the equipment employed. NMR was registered at the U26 facility of ICTS "NANBIOSIS" at the Universitat of València.

Keywords: alendronate $\cdot$ enzymes: cathepsin $\mathrm{K} \cdot$ nanoparticles - Osteoporosis

\section{References:}

[1] A. Qaseem, M. A. Forciea, R. M. McLean, T. D. Denberg, Ann Intern Med. 2017, 166, 818-839.

[2] a) J. A. Cramer, D. T. Gold, S. L. Silverman, E. M. Lewiecki, Osteoporos Int. 2007, 18, 1023-1031; b) N. B. Watts, D. L. Diab, J. Clin. Endocrinol. Metab. 2010, 95, 1555-1565.

[3] K. L. Kavanagh, K. Guo, J. E. Dunford, X. Wu, S. Knapp, F. H. Ebetino, M. J. Rogers, R. G. Russell, U. Oppermann, Proc Natl Acad Sci U S A 2006, 103, 7829-7834.

[4] L. Ochiuz, C. Grigoras, M. Popa, I. Stoleriu, C. Munteanu, D. Timofte, L. Profire, A. G. Grigoras, Molecules 2016, 21, 858.A.

[5] a) V. B. Junyaprasert, B. Morakul, Asian J. Pharm. Sci. 2015, 10, 13 23; b) M. A. Elgadir, M. S. Uddin, S. Ferdosh, A. Adam, A. J. K Chowdhury, M. I. S. Zaidul, J. Food Drug Anal. 2015, 23, 619-629.

[6] F. Farjadian, A. Ghasemi, O. Gohari, A. Roointan, M. Karimi, M. R. Hamblin, Nanomedicine 2019, 14, 93-126.

[7] F. Farjadian, A. Roointan, S. Mohammadi-Samani, M. Hosseini, Chem. Eng. J. 2019, 359, 684-705. 
[8] a) Y. Zhang, J. Wang, X. Bai, T. Jiang, Q. Zhang, S. Wang, Mol. Pharm. 2012, 9, 505-513; b) R. Mellaerts, R. Mols, J. A. G. Jammaer, C. A. Aerts, A. Annaert, J. Van Humbeeck, G. Van den Mooter, P. Augustijns, J. A. Martens, Eur. J. Pharm. Biopharm. 2008, 69, 223-230 c) A. Mehmood, H. Ghafar, S. Yaqoob, U. F. Gohar, B. Ahmad, J. Dev. Drugs 2017, 6, 1000174.

[9] a) F. Balas, M. Manzano, P. Horcajada, M. Vallet-Regí, J. Am. Chem. Soc. 2006, 128, 8116-8117; b) M. Manzano, G. Lamberti, I. Galdi, M Vallet-Regí, AAPS PharmSciTech. 2011, 12, 1193-1199.

[10] a) I. Candel, E. Aznar, L. Mondragón, C. de la Torre, R. MartínezMáñez, F. Sancenón, M. D. Marcos, P. Amorós, C. Guillem, E. PérezPayá, A. Costero, S. Gil, M. Parra, Nanoscale 2012, 4, 7237-7245; b) C. de la Torre, L. Domínguez-Berrocal, J. R. Murguía, M. D. Marcos, R. Martínez-Máñez, J. Bravo, F. Sancenón, Chem Eur J. 2018, 24, 18901897 ; c) L. A. Juárez, E. Añón, C. Giménez, R. Martínez-Máñez, F. Sancenón, A. M. Costero, P. Gaviña, M. Parra, A. Bernardos, Chem Eur J. 2016, 22, 14126-14130; d) K. Patel, S. Angelos, W. R. Dichtel, A. Coskun, Y. W. Yang, J. I. Zink, J.F. Stoddart, J. Am. Chem. Soc. 2008, 130, 2382-2383; e) Y. L. Sun, Y. Zhou, Q. L. Li, Y.-W. Yang, Chem Commun. 2013, 49, 9033-9035; f) X. Chen, A. H. Soeriyadi, X. Lu, S. M. Sagnella, M. Kavallaris, J. J. Gooding, Adv Func. Mater. 2014, 24 6999-7006.

[11] S. Alberti, G. J. A. A. Soler-Illia, A. Azzaroni, Chem. Commun. 2015, 51, 6050-6075.

[12] I. Slowing, B. G. Trewyn, V. S.-Y. Lin, J. Am. Chem. Soc. 2006, 128 , 14792-14793.

[13] a) L. Pascual, I. Baroja, E. Aznar, F. Sancenon, M. D. Marcos, J.R. Murguia, P. Amoros, K. Rurack, R. Martinez-Manez, Chem. Commun. 2015, 51, 1414-1416; b) M. Oroval, E. Aznar, C. Coll, M. D. Marcos, F. Sancenon, R. Martinez-Manez, P. Diez, R. Villalonga, Chemistry 2017 23, 1353-1360; c) A. H. Teruel, E. Perez-Esteve, I. Gonzalez-Alvarez, M. Gonzalez-Alvarez, A. M. Costero, D. Ferri, P. Gavina, V. Merino, R Martinez-Manez, F. Sancenon, Mol. Pharm. 2019,16, 2418-2429; d) A.H. Teruel, C. Coll, A. M. Costero, D. Ferri, M. Parra, P. Gavina, M. Gonzalez-Alvarez, V. Merino, M. D. Marcos, R. Martinez-Manez, F Sancenon, Molecules 2018, 23, 375/1 375/13.

[14] F. H. Drake, R. Dodds, I. James, J. Connor, C. Debouck, S. Richardson, E. Lee, D. Rieman, R. Barthlow, G. Hastings, M. Gowen, J. Biol. Chem. 1996, 271, 12511-12516.

[15] M. F. M. Alves, L. Puzer, S. S. Cotrin, M.A. Juliano, L. Juliano, D. Brömme, A.K. Carmona, Biochem. J. 2003, 373, 981-986.

[16] a) S. Cabrera, J. El Haskouri, C. Guillem, J. Latorre, A. Beltrán, D. Beltrán, M. D. Marcos, P. Amorós, Solid State Sci. 2000, 2, 405- 420; b) D. R. Radu, C.-Y. Lai, K. Jeftinija, E. W. Rowe, S. Jeftinija, V. S. Lin, J. Am. Chem. Soc. 2004, 126, 13216-13217.

[17] M. I. Walash, M. E.-S. Metwally, M. Eid, R. N. El-Shaheny, Chem. Cent. J. 2012, 6, 25 .

[18] a) M. F. Manolson, H. Yu, W. Chen, Y. Yao, K. Li, R.L. Lees, J. N. M. Heersche, J. Biol. Chem. 2003, 278, 49271-49278; b) B. L. V. Cuetara T. N. Crotti, A. J. O'Donoghue, K. P. Mchugh, In Vitro Cell. Dev. Biol. Anim. 2006, 42, 182-188.

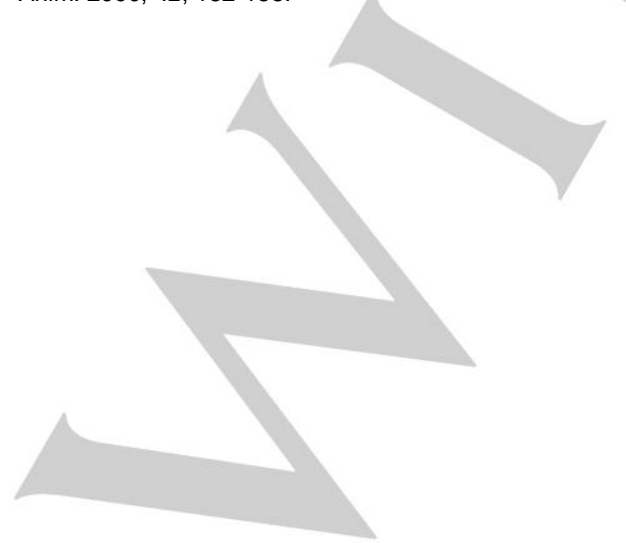




\section{Entry for the Table of Contents}

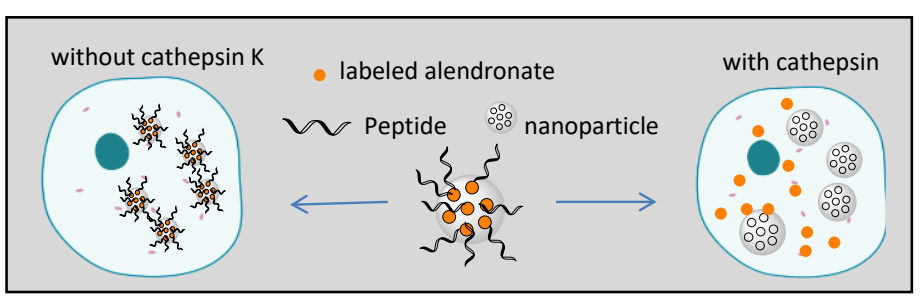

We describe nanoparticles $\mathbf{S 1}$ and $\mathbf{S} 2$ that were loaded with sulforhodamine B and alendronate and capped with a peptide that could be selectively hydrolyzed by cathepsin K enzyme Both nanoparticles were internalized by RAW 264.7 macrophages and were able to release its entrapped cargo in the presence of cathepsin $\mathrm{K}$ added in the macrophage lysates. Using S2 nanoparticles $4.2 \%$ of the total alendronate amount in contact with the cells is liberated inside them. 